\title{
Putative invasive pulmonary aspergillosis within medical wards and intensive care units: a 4-year retrospective, observational, single-centre study
}

\author{
Silvia Corcione ${ }^{1,2} \cdot$ Tommaso Lupia $^{1}\left[\right.$. Stefania Raviolo ${ }^{1}$. Giorgia Montrucchio ${ }^{1} \cdot$ Alice Trentalange $^{1}$. \\ Antonio Curtoni $^{3} \cdot$ Rossana Cavallo ${ }^{3} \cdot$ Francesco Giuseppe De Rosa $^{1}$
}

Received: 3 October 2020 / Accepted: 8 March 2021 / Published online: 22 March 2021

(c) The Author(s) 2021

\begin{abstract}
Blot and colleagues have proposed putative invasive pulmonary aspergillosis (PIPA) definitions for troublesome diagnosis in suspected patients outside the classical criteria of immunosuppression. We retrospectively included in the study all admitted patients with an Aspergillus spp. positive culture within lower airway samples. Overall, Aspergillus spp. positivity in respiratory samples was 0.97 every 1000 hospital admissions (HA): 4.94 and 0.28/1000/HA, respectively, in intensive care units (ICUs) and medical wards (MW). 66.6\% fulfilled PIPA criteria, and 33.4\% were defined as colonized. 69.2\% of PIPA diagnosis occurred in the ICU. Antifungal therapy was appropriate in $88.5 \%$ of subjects with PIPA and $37.5 \%$ of colonized, confirming the comparison between deads and lives. Patients with PIPA in the ICUs had more frequent COPD, sepsis or septic shock, acute kidney injury (AKI), needed more surgery, mechanical ventilation (MV), vasopressors, hemodialysis, blood or platelets transfusions. PIPA in MW had associated with a history of smoking, interstitial lung disease and inhaled steroid therapy. Overall mortality within 21 days was 50\%: 54.2\% in ICU, 36,8\% in MW. Factors associated with death were length of hospitalization, influenza, pneumonia, liver transplant, AKI, ARDS, sepsis and septic shock. PIPA in the ICU had higher disease severity and needed more organ support than MW cases, despite that cases of PIPA in MW are emerging with trends difficult to demonstrate given the problematic diagnosis.
\end{abstract}

Keywords Aspergillosis $\cdot$ Pneumonia $\cdot$ Putative $\cdot$ Medical wards $\cdot$ Fungi

\section{Introduction}

Invasive fungal infections (IFIs) are well categorized in hematological and severely immunosuppressed patients. According to the recently revised and updated definitions of the European Organization for Research and Treatment of Cancer/Mycosis Study Group (EORTC/MSG) [1], IFIs are classified as proven, probable or possible. Diagnosis of IFIs is based on the presence of a combination of classical host factors (e.g., neutropenia, hematopoietic stem cell

Tommaso Lupia

tommaso.lupia89@gmail.com

1 Department of Medical Sciences, Infectious Diseases, University of Turin, Turin, Italy

2 Tufts University School of Medicine, Boston, USA

3 Microbiology and Virology Unit, University of Turin, Turin, Italy transplant [HSCT], immunosuppressants or prolonged corticosteroid therapy) or recently added factors (e.g., severe inherited immunodeficiencies and low CD4 count), clinical features and positive mycology [1]. In addition to these factors, low doses of corticosteroids, chronic obstructive pulmonary disease (COPD), liver cirrhosis, systemic connective tissue diseases, influenza infection, diabetes mellitus and advanced solid cancer have been described as a favorable environment for IFIs, especially for invasive pulmonary aspergillosis (IPA) [2, 3]. These extends this conditions beyond hematological departments to primarily involve patients admitted to the intensive care unit (ICU) and medical wards (MWs) $[2,3]$. The signs and symptoms of IFIs have low specificity in these settings, and most diagnostic tests have only been validated in neutropenic hematologic or severely immunocompromised patients $[3,4]$. Thus, diagnosis is often troublesome and delayed [3, 4]. To solve this problem, a new definition of putative IPA (PIPA) has been proposed by Blot and colleagues [5] for patients who do 
not fulfill the EORTC/MSG criteria [1]. The definition is based on the contemporary presence of clinical and radiological criteria with risk factors in patients who have positive Aspergillus spp. cultures [3,5]. This study aimed to describe the epidemiology, risk factors, and clinical and prognostic features associated with a diagnosis of PIPA in a 4-year retrospective single-center analysis of hospitalized patients in the ICU. Additionally, the study extended the analysis to MW settings.

\section{Methods}

A retrospective, observational, monocentric study was conducted. The study included all patients with a positive Aspergillus spp. culture in lower airway samples obtained through bronchoalveolar lavage (BAL) or broncho-aspirate (BA) who were admitted between 01 January, 2012 and 31 December, 2016 to the MWs and ICU at Città Della Salute e Della Scienza di Torino-Presidio Molinette. Patients with a previous history of onco-hematological diseases (iron deficiency anemia, hemophilia, sickle cell disease, thalassemia, leukemias and lymphomas) or a history of IPA were excluded. Each patient's demographics and clinical and microbiological data were collected from electronic medical records and expressed as medians with interquartile ranges (IQRs). The incidence of positive culture was calculated on the thousandth hospital admission (HA). Signs and symptoms compatible with the clinical algorithm by Blot et al. [5] were reported along with the microbiological data. Positive Aspergillus spp. culture, blood galactomannan (GM) test, GM obtained through BAL or BA samples and a direct microscopic exam or polymerase chain reaction (PCR) for Aspergillus spp test positivity were collected. Mortality was evaluated 21 days after direct microbiological diagnosis (e.g., positive Aspergillus spp. culture, direct microscopic exam) or indirect diagnosis (e.g., GM). The study population was divided into three groups according to Blot et al. [5]. The first group included patients with a proven diagnosis of IPA according to the EORTC/MSG [1] definition (i.e., Aspergillus spp. positivity on microscopic analysis or cultures). The second group included patients with a diagnosis of PIPA who met all four following criteria:

1. Aspergillus-positive lower respiratory tract specimen culture (entry criterion).

2. Compatible signs and symptoms, including at least one of the following:

(a) Fever refractory to at least 3 days of appropriate antibiotic therapy. (b) Recrudescent fever after a period of defervescence of at least $48 \mathrm{~h}$, while still on antibiotics and without other apparent cause.

(c) Pleuritic chest pain.

(d) Pleuritic rub.

(e) Dyspnoea.

(f) Haemoptysis.

(g) Worsening respiratory insufficiency despite appropriate antibiotic therapy and ventilatory support.

3. Abnormal medical imaging by portable chest X-ray or CT scan of the lungs.

4. Either IVa or IVb.

(a) IVa host risk factors (one of the following conditions): neutropenia (absolute neutrophil count, $500 / \mathrm{mm} 3$ ) preceding or at the time of ICU admission, underlying hematological or oncological malignancy treated with cytotoxic agents, glucocorticoid treatment (prednisone equivalent, $20 \mathrm{mg} /$ day) and congenital or acquired immunodeficiency.

(b) IVb semiquantitative Aspergillus-positive culture of BAL fluid (+or ++ ) without bacterial growth together with a positive cytological smear showing branching hyphae

Group three included patients with Aspergillus spp. respiratory tract colonization (when $\geq 1$ criterion necessary for a diagnosis of PIPA was not met). Appropriate antifungal therapy at the time of microbiological positivity was retrospectively evaluated according to the currently available international guidelines from the Infectious Diseases Society of America (IDSA) and European Society of Clinical Microbiology and Infectious Diseases (ESCMID). Data were collected in an Excel spreadsheet and analysed the Statistical Package for the Social Sciences (SPSS) 18.0. continuous variables were reported as mean (standard deviation) or median (IQR). categorical variables were reported as absolute numbers (percentages). Non-parametric tests (Wilcoxon, Mann-Whitney, Chi-square and Fisher's exact tests) were used for univariate analyses. For categorical variables, Chi-square and Fisher's tests were used depending on the distribution of the contingency tables. Non-parametric tests (Wilcoxon and Mann-Whitney) were used for continuous variables, and Chi-square and Fisher's tests were used for categorical variables. The significance level was set at 0.05 to judge the strength of evidence for hypothesis testing. Factors presenting a significant level in the univariate analyses were included in the multivariate analyses (log regression) to assess for risk factors of death outcome. 


\section{Results}

During the study period, 80,570 patients were admitted to the ICUs and MWs. Overall, Aspergillus spp. positivity in the lower airway cultures (e.g., BAL or BA) was 0.97 for every 1000 HA distributed as follows: 4.94/1000 in the ICUs and 0.28/1000 in the MWs. Of these patients, 76 $(0.09 \%)$ fulfilled the criteria to be included in the study. The median age was 66.5 years old (range 58-77 years; $65.4 \%, \geq 60$ years), and the patients were mostly men (75.6\% male vs. $24.4 \%$ female). The median hospital length of stay (LOS) was 32 days (range 17.75.59 days), and the patients were hospitalized more frequently in the ICUs (76.3\%) than in the MWs (23.7\%). The algorithm for PIPA by Blot et al. [5] was applied to the patients. Of the 76 individuals, $52(68.4 \%)$ had a diagnosis of PIPA. Of these patients diagnosed with PIPA, $69.2 \%$ were hospitalized in the ICU, and $30.8 \%$ were hospitalized in the MWs. The remaining 24 patients did not fulfill the PIPA criteria, so microbiological positivity was considered as lower respiratory tract colonization in these patients. The main characteristics of the entire population are shown in Table 1. Regarding comorbidities, the majority of patients had cardiovascular disease (73.1\%), acute kidney injury $(51.3 \%)$ or diabetes $(42.3 \%)$. Other relevant comorbidities were COPD $(42.3 \%)$ or a history of malignancy $(34.6 \%)$; within the first group, $51.5 \%$ of the patients were undergoing daily chronic steroid inhalation therapy at home. At the time of microbiological positivity, $83.3 \%$ needed O2 therapy, $73.1 \%$ needed mechanical ventilation support, $64.1 \%$ needed hemodynamic and vasopressor support, $28.1 \%$ needed hemodialysis, and $96.2 \%$ had concomitant antibiotic therapy. Serum GM was positive in $20.9 \%$ of patients, with a median GM value of $1.96 \mathrm{ng} /$ $\mathrm{mL}(0.775-4.55 \mathrm{ng} / \mathrm{mL}$, normal value $<0.5 \mathrm{ng} / \mathrm{mL})$. However, a GM BAL/BA test was not performed in $17.8 \%$ of adults. GM on BAL or BA was positive in $98.2 \%$ of the tests, with a median value of $5.05 \mathrm{ng} / \mathrm{mL}(4.07-6.4 \mathrm{ng} /$ $\mathrm{mL}$; normal value $<0.5 \mathrm{ng} / \mathrm{mL}$ ). In the cultures, A. fumigatus was the species most frequently isolated $(72.9 \%)$, followed by A. terreus, A. flavus and A. niger. Additionally, $7(8.9 \%)$ adults had double species isolation during hospitalization. Furthermore, Aspergillus spp. isolation had some seasonal fluctuations and was found more often in winter (46.2\%) and spring (21.8\%). Of the patients, $73.1 \%$ were treated with an appropriate antifungal therapy at the moment of microbiological positivity. The majority $(89.5 \%)$ were treated with amphotericin B or voriconazole monotherapy ( $42.1 \%$ vs. $36.8 \%$, respectively), while the remaining patients were treated with caspofungin or posaconazole monotherapy or combination therapy. A univariate analysis was performed to assess the differences between patients with a diagnosis of PIPA and those colonized by Aspergillus spp. in both the ICUs and MWs. In patients from the ICUs, a diagnosis of PIPA was associated with more oral or intravenous steroid therapy during hospitalization, history of metastatic solid organ cancer, sepsis, features of pneumonia on X-rays or radiological abnormalities (Table 1). Furthermore, patients with PIPA in the ICUs were more frequently treated with antifungal therapy compared to colonized patients $(p<0.0001)$ and were treated before microbiologic results more often $(p=0.03)$. Additionally, ICU-infected patients underwent hemodialysis more commonly than colonized patients and had more respiratory insufficiency and worsening of respiratory insufficiency despite antibiotic therapy and adequate mechanical ventilation (Table 1). Subsequently, a univariate analysis (Table 1) was performed to assess the differences between patients with PIPA in the ICUs and MWs. Patients with PIPA in the ICUs presented more frequently with COPD, sepsis, septic shock and acute kidney failure. Moreover, ICU subjects needed surgical intervention or support therapies, such as mechanical ventilation, vasopressors, hemodialysis and blood or platelet transfusions, more often than patients in the MWs. Patients in the MWs were more likely to be smokers, had interstitial lung disease and had undergone chronic inhaled steroid therapy (Table 1). The estimation of mortality at day 21 was assessed from the microbiological positivity, and the overall mortality within 21 days was $51.3 \%$ (39 subjects). The mortality in the ICU was $82 \%$, as opposed to $17.9 \%$ in MW patients $(p=0.622) .37$ patients $(49.7 \%)$ survived: $25.3 \%$ went back home, $7.2 \%$ were transferred to another hospital, and $16.2 \%$ went to other facilities. Antifungal treatment was administered to $81.5 \%$ of the nonsurvivor patients diagnosed with PIPA and in $27.3 \%$ of the colonized dead patients. Characteristics in the univariate analysis (Table 2) associated with not survival were as follows: duration of hospitalization (longer in the live population, $p=0.006)$, influenza diagnosis $(p=0.048)$, possible pneumonia on radiological exams $(p=0.042)$, liver transplant $(p=0.048)$, acute kidney failure $(p<0.0001)$, acute respiratory distress syndrome (ARDS) $(p=0.019)$, sepsis $(p<0.0001)$, septic shock $(p<0.0001)$ and worsening of respiratory insufficiency in spite of mechanical ventilation $(p=0.003)$. Immunosuppressive drugs were associated with a lower risk of death $(p=0.002)$. According to the Blot et al. criteria, antifungal therapy was appropriate in $88.5 \%$ of patients with a diagnosis of PIPA and $37.5 \%$ of colonized patients, with a statistically significant difference in the univariate analysis $(p<0.0001)$. This association was confirmed after comparing non-survivor patients with alive ones $(p=0.001)$. Multivariate regression analysis (Tables 3,4 ) was performed for patients hospitalized in the ICU. The factors associated with PIPA included 
Table 1 Main characteristics of the study population

\begin{tabular}{|c|c|c|c|c|c|c|c|}
\hline & \multicolumn{2}{|l|}{$\operatorname{ICU}(n=58)$} & \multirow[t]{2}{*}{$p$ value } & \multicolumn{2}{|l|}{ MW $(n=18)$} & \multirow[t]{2}{*}{$p$ value } & \multirow{2}{*}{$\begin{array}{l}p \text { value } \\
\text { ICU vs. MW }\end{array}$} \\
\hline & $\begin{array}{l}\text { PIPA }(n=36) \\
n \text { median (IRQ) }\end{array}$ & $\begin{array}{l}\text { Colonization }(n=22) \\
n \text { median (IRQ) }\end{array}$ & & $\begin{array}{l}\text { PIPA }(n=16) \\
n \text { median (IRQ) }\end{array}$ & $\begin{array}{l}\text { Colonization }(n=2) \\
n \text { median (IRQ) }\end{array}$ & & \\
\hline \multicolumn{8}{|l|}{ Demographic variables } \\
\hline Gender (male) & 28 & 17 & 0.964 & 12 & 2 & 1 & 1 \\
\hline Age & $66.5(58-75.75)$ & $71(58-79.25)$ & 0.475 & $64.5(59.25-74.25)$ & $78(77-78)$ & 0.209 & 0.945 \\
\hline LOS & $37.5(19.5-68.5)$ & $32(17.75-53.5)$ & 0.553 & $25(14.5-42.25)$ & $41.5(28-41.5)$ & 0.399 & 0.730 \\
\hline $\begin{array}{l}\text { LOS from microbiologi- } \\
\text { cal diagnosis }\end{array}$ & $11.5(6-21.75)$ & $6(1.75-21.5)$ & 0.328 & $10.5(3.25-17)$ & $16.5(13-16.5)$ & 0.327 & 0.493 \\
\hline \multicolumn{8}{|l|}{ Comorbidities and risk factors } \\
\hline $\begin{array}{l}\text { Previous antibiotic treat- } \\
\text { ment }\end{array}$ & 32 & 16 & 0.156 & 15 & 2 & 1 & 1 \\
\hline Cardiovascular diseases & 28 & 15 & 0.418 & 12 & 2 & 0.490 & 1 \\
\hline Pneumonia & 19 & 4 & 0.013 & 12 & 2 & 1 & 0.220 \\
\hline COPD & 12 & 10 & 0.356 & 11 & 0 & 0.137 & 0.018 \\
\hline ILD & 3 & 4 & 0.409 & 5 & 0 & 1 & 0.035 \\
\hline Pancreatitis & 4 & 2 & 1 & 1 & 0 & 1 & 1 \\
\hline AKI & 25 & 10 & 0.070 & 5 & 0 & 1 & 0.010 \\
\hline CKD & 11 & 3 & 0.209 & 5 & 2 & 1 & 0.960 \\
\hline DM & 12 & 9 & 0.560 & 5 & 2 & 0.137 & 0.882 \\
\hline Cirrhosis & 6 & 4 & 1 & 4 & 1 & 0.490 & 0.475 \\
\hline \multicolumn{8}{|l|}{ Smoke } \\
\hline Present & 4 & 7 & 0.069 & 3 & 0 & 0.171 & 0.662 \\
\hline Former & 7 & 1 & & 8 & 0 & & 0.025 \\
\hline \multicolumn{8}{|l|}{ SOT } \\
\hline Lung & 0 & 1 & 0.379 & 5 & 0 & 1 & 0.002 \\
\hline Kidney & 3 & 1 & 1 & 1 & 0 & 1 & 1 \\
\hline Liver & 5 & 2 & 0.698 & 0 & 0 & - & 0.308 \\
\hline \multicolumn{8}{|l|}{ Malignancy } \\
\hline Primitive & 6 & 8 & 0.089 & 0 & 1 & 0.111 & 0.083 \\
\hline Metastatic & 9 & 0 & 0.010 & 3 & 0 & 1 & 0.733 \\
\hline Influenza co-infection & 4 & 2 & 1 & 1 & 0 & 1 & 1 \\
\hline $\begin{array}{l}\text { Steroids }>60 \text { days } \\
\quad(>1 \mathrm{mg} / \mathrm{kg} / \mathrm{d})\end{array}$ & 4 & 1 & 0.387 & 5 & 0 & 1 & 0.113 \\
\hline $\begin{array}{l}\text { Steroids }>21 \text { days } \\
(0.3 \mathrm{mg} / \mathrm{kg} / \mathrm{d})\end{array}$ & 7 & 1 & 0.139 & 7 & 0 & 0.497 & 0.094 \\
\hline $\begin{array}{l}\text { Steroids during hospitali- } \\
\text { zation }\end{array}$ & 28 & 4 & 0.000 & 13 & 0 & 0.235 & 1 \\
\hline Chronic steroid inhaler & 7 & 4 & 1 & 9 & 0 & 0.471 & 0.008 \\
\hline $\mathrm{CT}$ for malignancy & 5 & 0 & 0.145 & 4 & 0 & 1 & 0.431 \\
\hline $\begin{array}{l}\text { Neutropenia }(<500 \text { cell/ } \\
\left.\mathrm{mm}^{3}\right)\end{array}$ & 2 & 1 & 1 & 0 & 0 & - & 1 \\
\hline $\begin{array}{l}\text { Immunosuppressive } \\
\text { treatments }\end{array}$ & 7 & 3 & 0.727 & 6 & 0 & 0.529 & 0.184 \\
\hline $\begin{array}{l}\text { HIV or inherited immu- } \\
\text { nodeficiency }\end{array}$ & 2 & 0 & 0.521 & 0 & 0 & - & 1 \\
\hline ARDS & 10 & 3 & 0.332 & 1 & 0 & 1 & 0.140 \\
\hline Sepsis & 30 & 13 & 0.041 & 5 & 1 & 1 & 0.000 \\
\hline Septic shock & 27 & 11 & 0.052 & 1 & 1 & 0.216 & 0.000 \\
\hline Prior TB & 1 & 0 & 1 & 1 & 0 & 1 & 0.525 \\
\hline No major risk factors & 24 & 18 & 0.243 & 7 & 2 & 0.471 & 0.120 \\
\hline
\end{tabular}


Table 2 Characteristics of the study population in univariate analysis

\begin{tabular}{|c|c|c|c|}
\hline & $\begin{array}{l}\text { Survivors }(n=39) \\
n \text { median (IRQ) }\end{array}$ & $\begin{array}{l}\text { Deceased ( } n=39) \\
n \text { median (IRQ) }\end{array}$ & $p$ value \\
\hline \multicolumn{4}{|l|}{ Demographics } \\
\hline Males & 28 & 31 & 0.429 \\
\hline Age & $63(57-72)$ & $71(59-78)$ & 0.066 \\
\hline LOS & $44(18-70)$ & $28(16-37)$ & 0.006 \\
\hline LOS from microbiological diagnosis & $9(2-17)$ & $13(6-13)$ & 0.107 \\
\hline ICU & 27 & 32 & 0.622 \\
\hline MW & 12 & 7 & \\
\hline \multicolumn{4}{|l|}{ Comorbidities } \\
\hline Previous antibiotics & 32 & 35 & 0.329 \\
\hline Cardiovascular diseases & 31 & 26 & 0.202 \\
\hline Pneumonia & 14 & 24 & 0.042 \\
\hline COPD & 17 & 16 & 0.819 \\
\hline ILD & 5 & 7 & 0.530 \\
\hline Pancreatitis & 4 & 3 & 1 \\
\hline AKI & 11 & 30 & 0.000 \\
\hline CKD & 8 & 13 & 0.202 \\
\hline $\mathrm{DM}$ & 14 & 14 & 1 \\
\hline Cirrhosis & 9 & 6 & 0.389 \\
\hline \multicolumn{4}{|l|}{ Smoke } \\
\hline Actual & 6 & 8 & 0.765 \\
\hline Former & 9 & 7 & \\
\hline \multicolumn{4}{|l|}{ SOT } \\
\hline Lung & 5 & 1 & 0.200 \\
\hline Kidney & 5 & 0 & 0.055 \\
\hline Liver & 6 & 1 & 0.048 \\
\hline \multicolumn{4}{|l|}{ Malignancy } \\
\hline Solid & 7 & 8 & 0.774 \\
\hline Metastatic & 8 & 4 & 0.347 \\
\hline Influenza co-infection & 1 & 6 & 0.048 \\
\hline Steroids $>60$ days ( $>1 \mathrm{mg} / \mathrm{kg} /$ day prednisone) & 6 & 4 & 0.737 \\
\hline Steroids $>21$ days $(0.3 \mathrm{mg} / \mathrm{kg} /$ die prednisone $)$ & 8 & 8 & 1 \\
\hline Steroids & 23 & 23 & 0.890 \\
\hline Chronica inhaled steroids & 12 & 8 & 0.300 \\
\hline Malignancy during chemotherapy & 6 & 3 & 0.288 \\
\hline Neutropenia $\left(<500\right.$ cell $\left./ \mathrm{mm}^{3}\right)$ & 2 & 1 & 1 \\
\hline Immunosuppressive therapies & 14 & 2 & 0.001 \\
\hline HIV/AIDS & 1 & 1 & 1 \\
\hline ARDS & 3 & 12 & 0.019 \\
\hline Sepsis & 14 & 36 & 0.000 \\
\hline Septic shock & 8 & 33 & 0.000 \\
\hline Previous lung tubercolosis & 2 & 1 & 1 \\
\hline No major risk factors & 22 & 30 & 0.055 \\
\hline \multicolumn{4}{|l|}{ Therapy } \\
\hline Antifungal & 31 & 26 & 0.202 \\
\hline Switch & 10 & 4 & 0.139 \\
\hline Antifungal prophylaxis & 16 & 19 & 0.495 \\
\hline \multicolumn{4}{|l|}{ Symptoms } \\
\hline Dispnoea & 12 & 19 & 0.105 \\
\hline Fever & 8 & 12 & 0.300 \\
\hline Recurrent fever & 8 & 11 & 0.429 \\
\hline
\end{tabular}


Table 2 (continued)

\begin{tabular}{llll}
\hline & $\begin{array}{l}\text { Survivors }(n=39) \\
n \text { median (IRQ) }\end{array}$ & $\begin{array}{l}\text { Deceased }(n=39) \\
n \text { median (IRQ) }\end{array}$ & $p$ value \\
\hline Pleurodynia & 1 & 1 & 1 \\
Pleuric rub & 5 & 8 & 0.362 \\
Hemottysis & 3 & 1 & 0.615 \\
Acute respiratory failure & 6 & 18 & 0.003 \\
Imaging & 33 & 36 & 0.288 \\
Typical & 7 & 10 & 0.849 \\
Supportive therapies & & & \\
Oxygen & 29 & 36 & 0.0 .65 \\
Mechanical ventilation & 24 & 33 & 0.040 \\
Vasopressors & 17 & 33 & 0.000 \\
Hemodialysis & 6 & 16 & 0.012 \\
Blood transfusion & 23 & 32 & 0.025 \\
Platelets transfusion & 5 & 13 & 0.032 \\
Surgery & 22 & 20 & 0.650 \\
Antibiotics & 37 & 38 & 0.556 \\
Microbiology & & & 0.721 \\
GM serum & 4 & 5 & 0.491 \\
GM BAL/BA & 26 & 28 & 0.146 \\
Aspergillus DNA & 14 & 10 & \\
\hline
\end{tabular}

$L O S$ lenght of stay, $G M$ galattomannan, $A R D S$ acute respiratory distress syndrome, $B A L$ bronchoalveolar lavage, $B A$ broncho-aspirate, $I C U$ intensive care unit, $M W$ medical ward, $C O P D$ chronic obstructive pulmonary disease, $I L D$ interstitial lung disease, $D M$ diabete mellitus, $C K D$ chronic kidney disease, $A K I$ acute kidney injury, SOT solid organ transplant

Table 3 Risk factors for putative invasive pulmonary aspergillosis in multivariate analysis

\begin{tabular}{lllll}
\hline & $p$ value & a OR & \multicolumn{2}{l}{$95 \%$ CI } \\
\cline { 3 - 5 } & & & Inferior & Superior \\
\hline Steroids & 0.001 & 12.950 & 2.990 & 56.086 \\
Worsening of respiratory failure & 0.342 & 2.310 & 0.411 & 12.989 \\
Sepsis & 0.419 & 2.014 & 0.368 & 11.013 \\
Lack of antifungal therapy & 0.004 & 10.430 & 2.123 & 51.256 \\
Hemodialysis & 0.374 & 0.414 & 0.059 & 2.888 \\
\hline
\end{tabular}

$a O R$ adjusted odd ratio, $C I$ confidence interval

Table 4 Characteristics associated with 21-day mortality in multivariate analysis

\begin{tabular}{lllll}
\hline & $p$ value & a OR & \multicolumn{2}{l}{$95 \%$ CI } \\
\cline { 3 - 5 } & & & Inferior & Superior \\
\hline Acute kidney failure & 0.000 & 9.139 & 2.892 & 28.878 \\
Worsening of respiratory failure & 0.029 & 4.159 & 1.153 & 15.000 \\
Liver transplant & 0.034 & 0.066 & 0.005 & 0.812 \\
Influenza co-infection & 0.206 & 4.751 & 0.425 & 53.160 \\
\hline
\end{tabular}

$a O R$ adjusted Odd ratio, $C I$ interval of confidence is often hazardous due to the underlying conditions of the patients. Additionally, the diagnosis of probable or possible IPA according to EORTC/MSG [1] requires an immunocompromised host, which excludes the vast majority of the ICU and MW population [2-5]. This study reported a noticeable incidence of Aspergillus spp. positivity on lower airway cultures in the ICU population (4.94/1000 HA) over 4 years. The incidence is particularly noticeable when compared to longer studies in the same setting, such as the 14-year French retrospective study by Lugosi et al. [6]. They examined 11,992 patients admitted to ICUs and found that 9.08/1000 HA had Aspergillus spp. positivity in the lower airway cultures. Moreover, in an 18-month surveillance program involving 18 Italian ICUs, the incidence of IPA was 2.3/1000 HA [7], although IPA has been considered a rare condition among critically ill patients, but with a deadly mortality between 60 and $90 \%$ $[8,9]$. Furthermore, data on overall positivity in MWs are substantially lacking in the literature. Russo et al. [10] reported clinical features from 1351 subjects extrapolated during a 14-month period of infectious disease consultation in a tertiary care hospital in Italy. They found 14 cases of proven or probable invasive aspergillosis enrolled in medical and surgical wards. In the present analysis, the 
incidence of lower respiratory tract positivity for Aspergillus spp. among MWs was reported as 0.28/1000 HA. Within this group, 16 patients fulfilled the criteria for PIPA by Blot et al. [5]. Contrary to the case study by Russo et al. [10] that observed about $70 \%$ of PIPA cases in non-ICU wards, the present study described PIPA in just $30.8 \%$ of MWs adults with MWs. This discrepancy may have been related to a higher immunosuppressed MW population in the mentioned study [10] (e.g., high rate of malignancies, frequent cancer chemotherapies) and different diagnostic criteria. Advanced age and the predominance of males in the present study were comparable to the literature in this field $[2,5,6,10]$; this predominance of older men may be related to the higher incidence of comorbidities with PIPA in the aged population, notably chronic lung diseases, malignancies and chronic liver diseases. According to Matthaiou et al. [11], elderly patients were more likely to be diagnosed with PIPA than proven or possible IPA, due to less diagnostic radiological findings concurring with a delayed diagnosis. Cardiovascular diseases (73.1\%) and diabetes $(42.3 \%)$ were the two most frequent comorbidities in this population, and the same distribution of underlying diseases $(13.0 \%$ and $7.8 \%$, respectively) was found in the study by Blot et al. [5], although at lower rates. A high prevalence of chronic lung diseases (42.3\%) was found in this study, and this disease was more frequent among patients with PIPA in the MWs. Indeed, acute exacerbations in COPD were a cause of frequent admission to the MWs and ICUs. In an observational multicenter study of 563 critically ill patients with PIPA or Aspergillus spp. colonization, COPD was the most frequent underlying condition, involving $31 \%$ of adults [12]. Delsuc [13] and colleagues have described in a cohort of 677 COPD subjects admitted to the ICU that PIPA was a strong death predictor in critically ill patients; therefore, the use of corticosteroids and antibiotics before ICU admission was a risk factor for the development of PIPA. Moreover, acute kidney injury (AKI) and chronic kidney disease are underreported in most other studies. The present study found that AKI resulted in a mortality risk factor. Nevertheless, higher organ support was associated with more PIPA diagnoses, notably in the ICU setting, than reported by other authors [5-9]. In the present study, MW patients included more past or former smokers, interstitial lung diseases and chronic inhaled steroid therapies than ICU patients. Regarding the association between smoking and IFIs, Pourbaix et al. [10, 14] found an increased risk of fungal infections among smokers and recommended the implementation of smoking cessation strategies, especially in high-risk groups, such as HIV or hematological patients. However, ICU and MW patients were not included in their discussion. A. fumigatus was the most isolated species, followed by A. terreus. A. terreus has not been discussed frequently in the literature, except in some specific geographic areas $[11,15,16]$. This is of particular importance for therapy choice since A. terreus is resistant to amphotericin B, a first-choice therapy in invasive aspergillosis, along with voriconazole and isavuconazole $[11,15,16]$. The mortality of the current study's population was similar to neutropenic and non-neutropenic populations affected by aspergillosis. No difference in mortality was found between patients with PIPA and colonized patients. This observation was recently confirmed by Paiva et al. among ICUs in which patients with putative/ proven IPA were more likely to receive antifungal therapies than colonized patients (78.7\% vs. 25.5$)$.. As shown in the present study, Aspergillus isolation must not always be considered as simple colonization or contamination in immunocompromised patients, as IPA can also occur in patients who lack classical risk factors, like neutropenia or therapies with immunosuppressant drugs. The mortality for IPA in non-neutropenic is comparable to neutropenic patients, and high comorbidities in the MWs, along with the ICU population as reported in other studies [17, 18] and must be screened in the absence of other compatible diagnoses for IPA.

There are several limitations to this study. First, this is a single-centre study. Our patient population may not accurately reflect the general demographics of Italy. Second, there are some missing data, such as information regarding APS or APACHE score for ICU patients and in mortality analysis and GOLD classification in COPD patients. Third, the low numerosity of the sample included in our study.

In conclusion, in our study, MW patients primarily suffered from underlying respiratory diseases such as pneumonia and COPD, whereas ICU patients had a wider range of comorbid conditions, higher disease severity and needed more organ support.

Funding Open access funding provided by Università degli Studi di Torino within the CRUI-CARE Agreement.

Availability of data and materials Available on affordable request.

\section{Declarations}

Conflict of interest All authors have no conflicts of interest to declare.

Statements on human and animal rights Data acquisition and analysis was performed in compliance with protocols approved by the Ethical Committee of Città della Salute e della Scienza, Turin, Piedmont, Ethics Committee; Ethical approval number 0031285. The study was conducted according to the guidelines of the Declaration of Helsinki.

Informed consent For this type of study, no informed consent is required. 
Open Access This article is licensed under a Creative Commons Attribution 4.0 International License, which permits use, sharing, adaptation, distribution and reproduction in any medium or format, as long as you give appropriate credit to the original author(s) and the source, provide a link to the Creative Commons licence, and indicate if changes were made. The images or other third party material in this article are included in the article's Creative Commons licence, unless indicated otherwise in a credit line to the material. If material is not included in the article's Creative Commons licence and your intended use is not permitted by statutory regulation or exceeds the permitted use, you will need to obtain permission directly from the copyright holder. To view a copy of this licence, visit http://creativecommons.org/licenses/by/4.0/.

\section{References}

1. Donnelly JP, Chen SC, Kauffman CA, Steinbach WJ, Baddley JW, Verweij PE et al (2020) Revision and update of the consensus definitions of invasive fungal disease from the European Organization for Research and Treatment of Cancer and the Mycoses Study Group Education and Research Consortium. Clin Infect Dis. https://doi.org/10.1093/cid/ciz1008Blot

2. Falcone M, Concia E, Iori I, Lo Cascio G, Mazzone A, Pea F et al (2014) Identification and management of invasive mycoses in internal medicine: a roadmap for physicians. Intern Emerg Med 9(5):501-511. https://doi.org/10.1007/s11739-014-1077-4 (Epub 2014 May 29)

3. Blot S, Rello J, Koulenti D (2019) Diagnosing invasive pulmonary aspergillosis in ICU patients: putting the puzzle together. Curr Opin Crit Care 25(5):430-437. https://doi.org/10.1097/MCC. 0000000000000637

4. Danion F, Rouzaud C, Duréault A, Poirée S, Bougnoux ME, Alanio A (2019) Why are so many cases of invasive aspergillosis missed? Med Mycol 57:S94-S103

5. Blot SI, Taccone FS, Van den Abeele AM, Bulpa P, Meersseman W, Brusselaers $\mathrm{N}$ et al (2012) A clinical algorithm to diagnose invasive pulmonary aspergillosis in critically ill patients. Am J Respir Crit Care Med 186:56-64

6. Lugosi M, Alberti C, Zahar JR, Garrouste M, Lemiale V, Descorps-Desclère A et al (2014) Aspergillus in the lower respiratory tract of immunocompetent critically ill patients. J Infect 69(3):284-292. https://doi.org/10.1016/j.jinf.2014.04.010

7. Montagna MT, Caggiano G, Lovero G, De Giglio O, Coretti C, Cuna $\mathrm{T}$ et al (2014) Epidemiology of invasive fungal infections in the intensive care unit: results of a multicenter Italian survey (AURORA Project). Infection 42:141-151

8. Meersseman W, Vandecasteele SJ, Wilmer A, Verbeken E, Peetermans WE, Van Wijngaerden E (2004) Invasive aspergillosis in critically ill patients without malignancy. Am J Respir Crit Care Med 170:621-625

9. Dimopoulos G, Piagnerelli M, Berré J, Eddafali B, Salmon I, Vincent JL (2003) Disseminated aspergillosis in intensive care unit patients: an autopsy study. J Chemother. 15:71
10. Russo A, Falcone M, Vena A, Venditti C, Mancini C, Morelli A et al (2011) Invasive pulmonary aspergillosis in non-neutropenic patients: analysis of a 14-month prospective clinical experience. J Chemother 23:290-294

11. Matthaiou DK, Dimopoulos G, Taccone FS et al (2018) Elderly versus non-elderly patients with invasive aspergillosis in the ICU: a comparison and risk factor analysis for mortality from the AspICU cohort. Med Mycol 56(6):668-678. https://doi.org/10. 1093/mmy/myx 117

12. Taccone FS, Van den Abeele AM, Bulpa P, Misset B, Meersseman W, Cardoso T et al (2015) Epidemiology of invasive aspergillosis in critically ill patients: clinical presentation, underlying conditions, and outcomes. Crit Care 19:7. https://doi.org/10.1186/ s13054-014-0722-7

13. Levesque E, Ait-Ammar N, Dudau D, Clavieras N, Feray C, Foulet $\mathrm{F}$ et al (2019) Invasive pulmonary aspergillosis in cirrhotic patients: analysis of a 10-year clinical experience. Ann Intensive Care 9(1):31. https://doi.org/10.1186/s13613-019-0502-2

14. Pourbaix A, Lafont Rapnouil B, Guéry R, Lanternier F, Lortholary O, Cohen JF (2020) Smoking as a risk factor for invasive fungal disease: systematic review and meta-analysis. Clin Infect Dis. https://doi.org/10.1093/cid/ciaa001

15. Pérez-Cantero A, López-Fernández L, Guarro J, Capilla J (2020) Azole resistance mechanisms in Aspergillus: update and recent advances. Int J Antimicrob Agents 55(1):105807. https://doi.org/ 10.1016/j.ijantimicag.2019.09.011

16. Paiva JA, Mergulhão P, Gomes A et al (2017) Drivers and impact of antifungal therapy in critically ill patients with Aspergilluspositive respiratory tract cultures. Int J Antimicrob Agents 50(4):529-535. https://doi.org/10.1016/j.ijantimicag.2017.05.017

17. Loughlin L, Hellyer TP, White PL, McAuley DF, Conway Morris A, Posso RB, Richardson MD, Denning DW, Simpson AJ, McMullan R (2020) Pulmonary Aspergillosis in patients with suspected ventilator-associated pneumonia in UK ICUs. Am J Respir Crit Care Med 202(8):1125-1132. https://doi.org/10.1164/ rccm.202002-0355OC

18. Schauwvlieghe AFAD, Rijnders BJA, Philips N, Verwijs R, Vanderbeke L, Van Tienen C, Lagrou K, Verweij PE, Van de Veerdonk FL, Gommers D, Spronk P, Bergmans DCJJ, Hoedemaekers A, Andrinopoulou ER, van den Berg CHSB, Juffermans NP, Hodiamont CJ, Vonk AG, Depuydt P, Boelens J, Wauters J, DutchBelgian Mycosis study group (2018) Invasive aspergillosis in patients admitted to the intensive care unit with severe influenza: a retrospective cohort study. Lancet Respir Med. 6(10):782-792. https://doi.org/10.1016/S2213-2600(18)30274-1

Publisher's Note Springer Nature remains neutral with regard to jurisdictional claims in published maps and institutional affiliations. 